\title{
Response of Rat Intestine to a Hyperosmotic Feeding
}

\author{
SAUL TEICHBERG, ${ }^{1321}$ FIMA LIFSHITZ, ROBERT PERGOLIZZI, AND RAUL A. WAPNIR \\ Departments of Pediatrics and Laboratories, North Shore University Hospital, Manhasset, and Department of \\ Pediatrics, Cornell University Medical College, New York, New York, USA
}

\begin{abstract}
Summary
After a single force-feeding of hypertonic (1300 mOsm) mannitol to rats there is rapid osmotic equilibration of the jejunal fluid, a sharp drop in luminal mannitol concentration and large influxes of water and sodium. During osmotic equilibration there was a significant loss of cells from the jejunal mucosa. In hypertonically fed rats there was an accumulation of protein, DNA, $\left[{ }^{3} \mathrm{H}\right]$ thymidinelabeled DNA, and disaccharidases in intestinal washings. Brush border disaccharidase specific activities on the jejunal mucosa were unaltered. Under the light microscope jejunal villi from hypertonic mannitol rats were comparable to controls. Some epithelial cells from rats force-fed hypertonic mannitol showed transient ultrastructural damage. Microvilli of some cells were shortened and fused at their bases 20 and $\mathbf{4 0} \mathrm{min}$ after the forcefeeding. By $120 \mathrm{~min}$ epithelial cell microvilli were all normal in appearance. In hypertonically fed rats the lateral interdigitating plasma membranes became disorganized. Large fragments budded off into one cell and fused to form larger structures. By $120 \mathrm{~min}$ many lysosomal autophagic vacuoles and residual bodies were seen. A single hypertonic force feeding produced jejunal cell loss associated with loss of brush border disaccharidases and focal ultrastructural damage.
\end{abstract}

\section{Speculation}

The damage induced in the jejunal mucosa of rats by a hypertonic feeding may provide clues concerning the pathophysiology of certain clinical conditions. Damage to the lateral interdigitating plasma membranes of adjacent epithelial cells could reflect alterations in permeability allowing the passage of bacterial toxins or allergens into the circulation, or permitting massive bacterial gas leakage leading to pneumatosis intestinalis. The loss of jejunal cells and parallel loss of disaccharidases into the intestinal lumen could, in part, account for the disaccharidase deficiences seen in diarrheal disease where osmotic pressure can become significant because of unabsorbed carbohydrate. This malabsorption may be further enhanced by microvillar alterations such as shortening and fusion, which significantly decrease the effective absorptive area.

Direct perfusion of hypertonic solutions into the small intestine produces a rapid response, including osmotic equilibration (10, $23)$ and morphologic $(14,19,23)$ and functional damage $(9,14$, 22). Small intestinal hyperosmotic stress, which occurs during diarrheal disease $(1,15)$ and in feedings of hyperosmotic elemental diets to newborn infants (3), may also lead to pathologic changes in the intestine. However, oral feedings of hyperosmotic mannitol did not produce any histologic damage to the intestinal mucosa of normal men (21).

In the present study we have evaluated the effects of a per oral hyperosmotic load upon the physiology and morphology of the small intestinal mucosa of the rat. Our results suggest that a single feeding of a hyperosmotic solution of mannitol produces significant damage to the jejunum. There is a loss of disaccharidase activity associated with a loss of mucosal epithelial cells and focal ultrastructural damage.

\section{MATERIALS AND METHODS}

Male Wistar strain rats (Carworth Animal Breeders, New City, NY) weighing $80-100 \mathrm{~g}$ were used. They were fed Purina lab chow plus tap water ad libitum. On the day of the experiment, four groups of six rats each were force-fed $5 \mathrm{ml} / 100 \mathrm{~g}$ body weight of a $1350 \mathrm{mOsm} /$ liter $(20 \%)$ mannitol solution by intragastric instillation. The solution also contained $5 \mu \mathrm{Ci} / 100 \mathrm{ml}$ of $\left[{ }^{3} \mathrm{H}\right]$ mannitol, specific activity, $2.65 \mathrm{Ci} / \mathrm{mM}$ (New England Nuclear, Boston, MA) and $600 \mathrm{mg} / 100 \mathrm{ml}$ polyethylene glycol (PEG), mol wt 3000-3700. Control rats were force-fed isotonic $(300$ $\mathrm{mOsm} /$ liter) mannitol or saline/ $100 \mathrm{~g}$ of body weight in addition to $\left[{ }^{3} \mathrm{H}\right]$ mannitol and PEG.

Rats were killed by decapitation immediately after the forcefeedings and after 20,40 , and $120 \mathrm{~min}$. The abdominal cavity was rapidly opened by a midline incision. The stomach and jejunum (20 cm segment of jejunum beginning at the ligament of Treitz) were rapidly isolated and clamped off. In rats intended for biochemical analysis of the small intestinal mucosa, the luminal contents of each segment were collected, stored on ice, and then frozen at $-20^{\circ}$. The jejunal mucosa was scraped with a glass slide, homogenized with 9 vol of isotonic saline in a glass tube with a Teflon pestle (Tri-R instruments Company, Rockville Center, $\mathrm{NY}$ ), and frozen at $-20^{\circ}$ until analysis. Similar experiments were performed on another four groups of six rats each injected (ip) with $1 \mu \mathrm{Ci} / \mathrm{g}$ body wt of $\left[{ }^{3} \mathrm{H}\right]$ thymidine specific activity, 47-59 $\mathrm{Ci} / \mathrm{mM}$ (New England Nuclear, Boston, MA) $24 \mathrm{hr}$ before the killing. In these animals, the intestinal tract was washed with $3 \mathrm{ml}$ isotonic saline and the luminal contents of the entire intestinal tract were collected and frozen at $-20^{\circ}$. During subsequent procedures, the washings were thawed and separated by centrifugation into pellet and supernatant fractions.

Sodium and potassium in gastric fluid and jejunal fluid were determined by flame photometry. Osmolality was determined by freezing point depression on a Precision Systems Osmette osmometer.

Mannitol concentrations in gastric and jejunal fluids were determined by isotope dilution of the $\left[{ }^{3} \mathrm{H}\right]$ mannitol using liquid scintillation counting (Beckman LS-230, Palo Alto, CA). The absolute amount of mannitol in the gastric fluid and jejunal fluid was also calculated by correction for dilution of PEG during the experiment.

The direction and relative extent of water flux in the gastric fluid and jejunal fluid was determined by plotting the changes in the ratio of initial to final PEG concentration $\left(\mathrm{PEG}_{\mathrm{i}} / \mathrm{PEG}_{\mathrm{f}}\right)$ at each time point studied. PEG was assayed according to Malawer and Powell (18).

Specific activities of intestinal disaccharidases (maltase, sucrase, and lactase) were determined in the jejunal mucosa and in the pellet and supernatant fractions derived from the fluid of the intestinal tract according to the Dahlqvist procedure (6), and 
expressed as micromoles of substrate hydrolyzed per min per $\mathrm{mg}$ protein and per min per mg mucosal DNA. Protein was determined according to Lowry (17). All enzyme assays were carried out within 1 week after freezing the sample.

DNA in the jejunal mucosa and in the pellet and supernatant derived from intestinal fluid was also determined after extraction according to the method of Schneider (26). Colorimetric determination of DNA concentration was done by the method of Siebert (27). Results were expressed as milligrams of DNA per mg mucosal protein.

Labeled DNA $\left(\left[{ }^{3} \mathrm{H}\right]\right.$ thymidine) was also assayed by liquid scintillation counting. These data were expressed as total disintegrations per min in supernatant or pellet.

In rats intended for morphologic studies, the jejunum was rapidly fixed for 4-24 hr in one of two ways: in one method, a ring of jejunum $10 \mathrm{~cm}$ distal to the ligament of Treitz was cut and rapidly immersed in ice-cold $2.5 \%$ glutaraldehyde buffered with $0.1 \mathrm{M}$ cacodylate $(\mathrm{pH} 7.2$ ) and sliced into thin cross-sectional rings; alternatively, some material was fixed by gentle perfusion of the jejunum with buffered fixative followed by immersion (28).

Glutaraldehyde-fixed tissue was briefly rinsed in cold buffer, postfixed in cold $1 \%$ osmium tetroxide in $0.1 \mathrm{M}$ cacodylate buffer for $1 \mathrm{hr}$, rinsed in cold $7.5 \%$ sucrose, stained en bloc (7) with uranyl acetate, rinsed in cold $7.5 \%$ sucrose, dehydrated in a graded series of ethanols and embedded in Epon.

One- to $2-\mu \mathrm{m}$ thick sections stained with toluidine blue were examined by light microscopy. Thin sections were cut on a PorterBlum MT2-B Ultramicrotome, stained with uranyl acetate plus lead citrate, and examined on a JEOL JEM-100 electron microscope. Micrographs were taken at initial magnifications of $4,000-15,000 \times$.

Table 1. Jejunal and gastric luminal fluid changes 0, 20, 40, and 120 min after an intragastric force-feeding of $20 \%$ mannitol solution ${ }^{1}$

\begin{tabular}{ccccc}
\hline $\begin{array}{c}\text { Lumen } \\
\text { contents }\end{array}$ & $\begin{array}{c}\text { Mannitol, } \\
\mathrm{mM} / \text { liter }\end{array}$ & $\begin{array}{c}\text { Osmolality, } \\
\mathrm{mOsm} / \mathrm{kg}\end{array}$ & $\begin{array}{c}\text { Water flux, } \\
\mathrm{PEG}_{\mathrm{i}} / \mathrm{PEG}_{\mathrm{f}}\end{array}$ & $\begin{array}{c}\text { Sodium flux, } \\
\mathrm{mEq} / \text { liter }\end{array}$ \\
\hline $\begin{array}{l}\text { Jejunal } \\
0 \mathrm{~min}\end{array}$ & $729 \pm 77.3$ & $872 \pm 27$ & $1.31 \pm .120$ & $40.3 \pm 7.41$ \\
$20 \mathrm{~min}$ & $388 \pm 93.8^{2}$ & $510 \pm 60^{3}$ & $2.43 \pm 0.59$ & $57.9 \pm 7.57$ \\
$40 \mathrm{~min}$ & $311 \pm 121^{2}$ & $429 \pm 122^{3}$ & $2.52 \pm 0.81$ & $77.9 \pm 4.63^{4}$ \\
$120 \mathrm{~min}$ & $222 \pm 54.8^{2}$ & $372 \pm 12^{3}$ & $2.96 \pm 0.39^{4}$ & $95.9 \pm 7.34^{4}$ \\
Stomach & & & & \\
$0 \mathrm{~min}$ & $755 \pm 257$ & $1291 \pm 27$ & $.923 \pm .036$ & $21.4 \pm 7.30$ \\
$20 \mathrm{~min}$ & $655 \pm 163$ & $1033 \pm 76^{2}$ & $1.08 \pm .075$ & $25.2 \pm 4.28$ \\
$40 \mathrm{~min}$ & $842 \pm 72.4$ & $1146 \pm 23^{4}$ & $1.04 \pm 0.11$ & $32.5 \pm 9.53$ \\
$120 \mathrm{~min}$ & $504 \pm 164$ & $846 \pm 103^{4}$ & $1.29 \pm 0.21$ & $34.4 \pm 10.9$ \\
\hline
\end{tabular}

${ }^{1}$ Note the decline in jejunal luminal mannitol concentration and jejunal and gastric osmolality. The increase in the ratio of $\mathrm{PEG}_{\mathrm{i}} / \mathrm{PEG}_{\mathrm{f}}$ is indicative of a large influx of water into the jejunal lumen. There is also a parallel luminal influx of sodium into the jejunal lumen. Mean \pm SEM. All $p$ values refer to basal levels. $n=6$ per group.

${ }^{2} P<0.05$.

${ }_{3}^{3} P<0.01$.

$+P<0.02$.

Table 2. Changes in total protein, total DNA, total ['H]thymidine-labeled DNA, and total international units (IU) of the lactase, sucrase, and maltase in supernatant fraction of intestinal washings of rats 0, 20,40, and 120 min after hyperosmotic mannitol force-feeding

\begin{tabular}{rcccccc}
\hline $\begin{array}{c}\text { Time, } \\
\text { min }\end{array}$ & Protein, $\mathrm{mg} / \mathrm{ml}$ & DNA, mg/ml & [ $^{3} \mathrm{H}$ DNA. dpm $/ \mathrm{min} / \mathrm{ml}$ & Lactose, total IU & Sucrase, total IU & Maltase, total IU \\
\hline 0 & $1.66 \pm .470$ & $0.158 \pm 0.025$ & $17.910 \pm 7.015$ & $0.0949 \pm 0.0662$ & $0.1491 \pm 0.0301$ & $0.1533 \pm 0.0419$ \\
20 & $4.22 \pm 1.77^{2}$ & $0.280 \pm 0.060^{3}$ & $49.173 \pm 14.173^{3}$ & $0.3005 \pm 0.3316$ & $1.0028 \pm 1.1447$ & $0.4359 \pm 0.3303$ \\
40 & $4.41 \pm 3.11^{4}$ & $0.350 \pm 0.080^{3}$ & $59.370 \pm 39.310^{2}$ & $0.2473 \pm 0.3458$ & $0.6727 \pm 0.9944$ & $0.6878 \pm 0.7052$ \\
120 & $4.15 \pm 1.14^{3}$ & $0.520 \pm 0.210^{3}$ & $178.514 \pm 78.039^{3}$ & $0.1935 \pm 0.0771^{4}$ & $1.4851 \pm 0.6697^{3}$ & $0.3758 \pm 0.1923^{4}$ \\
\hline
\end{tabular}

'Note the significant increase in all of these parameters by the end of the experimental period. Mean \pm SEM. All P values refer to basal levels. $n=$ 6 per group.

" $P<0.01$

${ }^{3} P<0.001$.

${ }^{4} P<0.05$.
A total of 48 rats were studied. Six paris of experimental and control rats were examined at each time point $(0,20,40$, and 120 $\mathrm{min})$ for histologic and ultrastructural alterations. For each rat studied we examined at least $10-20$ villi/rat by light microscopy. Samples of these villi from each of the rats were analyzed by electron microscopy. Our electron microscopic analysis was carried out in "blind" experiments in which the investigator was unaware of the physiologic treatments to which the material had been subjected.

\section{RESULTS}

\section{OSMOLALITY, SODIUM, AND WATER FLUXES}

After a single force-feeding of hypertonic (1300 mOsm) mannitol there was a rapid osmotic equilibration of the jejunal fluid as shown in Table 1. Osmolality decreased from an initial level of $872 \mathrm{mOsm}$ to near isotonic conditions by the end of the 120 -min experimental period. Jejunal osmotic equilibration was accompanied by a sharp drop in luminal mannitol concentration and influxes of large quantities of water and sodium into the jejunal lumen (Table 1).

The stomach retained most of the administered mannitol throughout the experimental period (Table 1). Gastric luminal osmolality decreased slowly and there were small influxes of water and sodium into the lumen of the stomach (Table 1).

In contrast to rats fed hypertonic mannitol, when rats were fed isotonic (300 mOsm) mannitol or saline the jejunal osmotic pressure remained isotonic, and there were no detectable fluxes of water and sodium into the jejunal lumen.

\section{MUCOSA: CELL TURNOVER AND DISACCHARIDASES}

There was a significant loss of cells from the jejunal mucosa during the period of osmotic equilibration following the hypertonic mannitol feeding. The concentration of DNA per $\mathrm{mg} \mathrm{mu-}$ cosal protein declined significantly after $120 \mathrm{~min}$ (from $0.260 \pm$ 0.010 at the time of the feeding to $0.180 \pm 0.006$ at $120 \mathrm{~min} ; P<$ DNA per mg mucosal protein was unaltered.

Brush border disaccharidases (lactase, sucrase, and maltase) on the jejunal mucosa were unaltered during the period of osmotic equilibration in rats fed a hyperosmotic load.

\section{INTESTINAL LUMEN: CELLS AND DISACCHARIDASES}

There was an accumulation of cellular materials in the lumen of the intestine of hypertonically fed rats. The supernatant fraction derived from the intestinal washings of these animals showed an accumulation of protein, DNA, $\left[{ }^{3} \mathrm{H}\right]$ thymidine-labeled DNA $\left(\left[{ }^{3} \mathrm{H}\right]\right.$ thymidine given $24 \mathrm{hr}$ before the experiment) throughout the experimental period (Table 2). Disaccharidase activities (lactase, sucrase and maltase) also increased in the supernatant fraction of the intestinal washings (Table 2). All of the above, with the exception of lactase, showed a similar rise in the pellet fraction derived from the intestinal washings. Lactase activity in the pellet was unchanged. 0.05 ). On the other hand, in isotonic controls the concentration of 

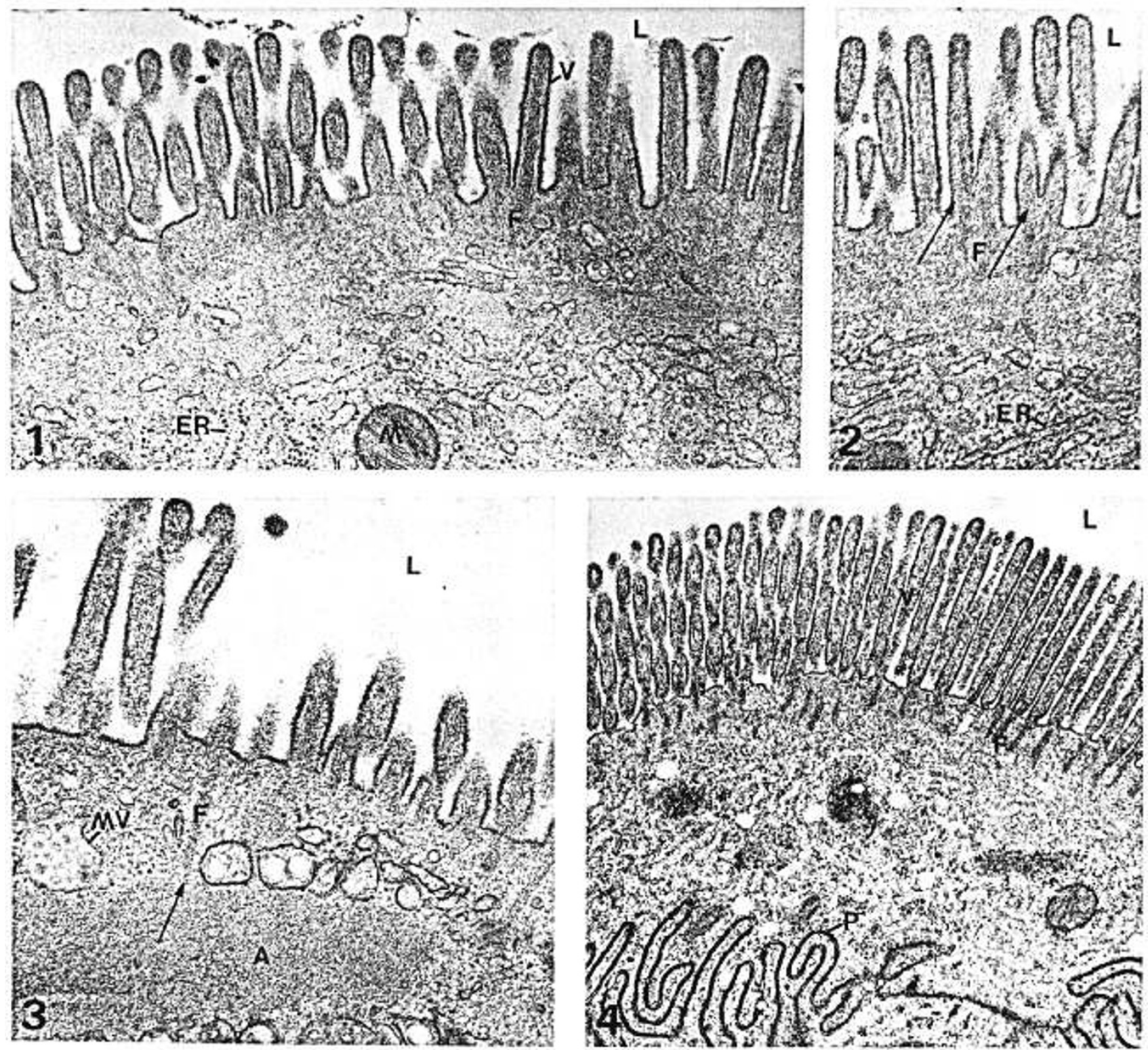

Fig. 1. Figures 1-9 are electron micrographs of rat jejunal epithelial cells stained with lead citrate and uranyl acetate. Portion of a rat jejunal absorptive epithelial cell $20 \mathrm{~min}$ after a hyperosmotic mannitol feeding. Many microvilli (V) appear shortened. Intestinal lumen is at $\mathrm{L}$, microfilaments at $F$, mitochondria at $M$, endoplasmic reticulum at $E R(\times 29,000)$.

Fig. 2. Microvilli on a jejunal absorptive epithelial cell $20 \mathrm{~min}$ after a mannitol feeding. Some microvilli appear to be fused at their bases (arrows) to form twinned (28) structures. Intestinal lumen is at $\mathbf{L}$, endoplasmic reticulum at $E R$, microfilaments at $F(\times 30,000)$.

Fig. 3. Portion of a jejunal absorptive epithelial cell $40 \mathrm{~min}$ after a hypertonic mannitol feeding. A large particulate aggregate (A) is seen in the terminal web region in one cell. Filaments from the core of a microvillus appear as if connected to the large aggregate (arrow). Intestinal lumen is at $L$, a multivesicular body at MV $(\times 64,000)$

Fig. 4. Rat jejunal absorptive epithelial cell $120 \mathrm{~min}$ after a mannitol feeding. Microvilli of a normal appearance are seen at $\mathrm{V}$. Intestinal lumen is at L, microfilaments at $F$, plasma membrane at $P(\times 21,000)$.

Fig. 5. Interdigitating lateral plasma membranes (arrows) of two adjacent jejunal absorptive epithelial cells from a 0 time rat. These plasma membranes normally form such a characteristic complex. $(\times 30,000)$

Fig. 6. Portion of a jejunal absorptive epithelial cell $20 \mathrm{~min}$ after a hyperosmotic mannitol feeding. Many fragments of the lateral interdigitating plasma membrane complex appear to have budded off into the cytoplasm of one of the cells and the whole complex appears disorganized. Ribosomes $(R)$ are seen in the lumen of some of the fragments. Intact adjacent plasma membranes of two cells are seen at arrows. The double membrane structure derived from these plasma membranes is seen at arrowheads. Filaments are seen at $F(\times 39,000)$.

Fig. 7. Portion of a jejunal epithelial cell $40 \mathrm{~min}$ after a mannitol feeding. The large structure (D) appears as if it were formed by the fusion of numerous smaller fragments of the interdigitating plasma membrane complex as seen in Figure 6 . Note the characteristic double membrane structure at arrowheads. Ribosomes are seen at $R$, mitochondria at $M$, Golgi apparatus at $G$, coated vesicle at V $(\times 40,000)$.

Fig. 8. Large dense membrane-delimited structure in a jejunal absorptive epithelial cell $40 \mathrm{~min}$ after a mannitol feeding. This dense body also appears to be derived from fragments of the lateral interdigitating plasma membrane complex. Characteristic double membraned structure is seen at arrowheads, ribosomes at $\mathrm{R}$. A chylomycra-like structure often found in the extracellular space between epithelial cells is at $\mathrm{C}(\times 35,000)$.

Fig. 9. Portion of a jejunal absorptive epithelial cell $120 \mathrm{~min}$ after a hypertonic mannitol feeding. The two large structures at $\mathrm{D}$ appear to be residual body stage lysosomes and contain a residue of lipid-like material that is not digested. Endoplasmic reticulum is at ER, mitochrondria at M $(\times 27,000)$. 


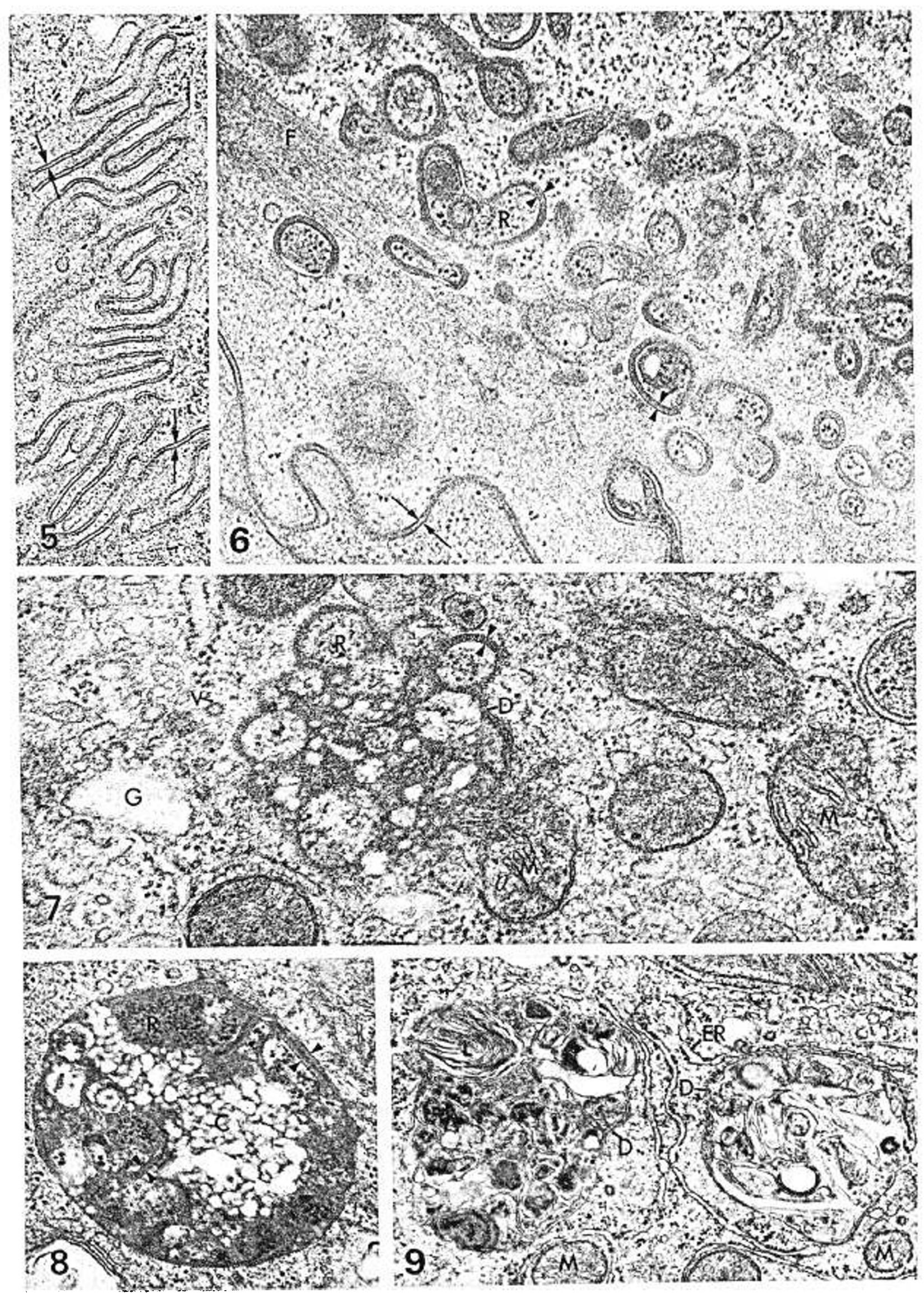




\section{MUCOSA: LIGHT MICROSCOPY}

Under the light microscope, jejunal villi from animals that were force-fed hypertonic mannitol appeared entirely comparable to villi from control animals; there were no detectable differences in villus height, no signs of extracellular swelling due to edema, and no marked shrinkage of epithelial cells.

\section{MUCOSA: ELECTRON MICROSCOPY}

Most of the abosrptive epithelial cells from animals that were force-fed hypertonic mannitol appeared intact. All the organelles in these cells, including microvillar brush border, terminal web, interdigitating lateral plasma membranes, Golgi apparatus, and lysosomes appeared normal. Since the rats were fed ad libitum before the experiment, there was some ultrastructural heterogeneity such as random signs of fat absorption in both experimental and control animals.

However, in occasional villi, from rats force-fed hypertonic mannitol, some jejunal epithelial cells showed signs of ultrastructural damage that were not apparent in control animals. Microvilli of some epithelial cells from these animals were noticeably shortened (Fig. 1) by 20 and 40 min after the hypertonic feeding. In some of these cells microvilli were seen that were fused at their bases to form a Y-shaped structure (Fig. 2; also see Ref. 28). In the terminal web region of some of these cells particulate aggregates were seen in images suggesting that they were connected to the microfilaments that extend through the core of microvilli (Fig. 3 ). By the end of the 120-min experimental period microvilli of almost all epithelial cells examined were normal in length and appearance (Fig. 4). None of these microvillar alterations were noted in control animals.

The lateral plasma membranes of adjacent absorptive epithelial cells normally interdigitate with one another to form an elaborate complex with junctional specializations (Fig. 5). In the villi of some animals force-fed hypertonic mannitol, these plasma membrane complexes became disorganized. By $20 \mathrm{~min}$, cells were seen in which large fragments of these lateral plasma membrane complexes were seen as if budding off into the cytoplasm of one of the two cells from which they were derived (Fig. 6). These budded off fragments carried, trapped in their lumen, numerous ribosomes (Fig. 6). By 40 min, many of these budded off fragments were seen in images, suggesting that they had fused to form larger structures (Fig. 7). By the end of the 120-min experimental period, many structures were seen that morphologically resembled lysosomal autophagic vacuoles and residial bodies (Figs. 8 and 9).

Other organelles in the jejunal epithelium were unaffected throughout the experimental period. None of these structural changes were noted in controls.

\section{DISCUSSION}

Our evidence suggests that a single force-feeding of a hypertonic load can produce significant alterations in the rat jejunal mucosa. During the osmotic equilibration following the force-feeding there was a significant loss of cells from the jejunum, a loss of brush border disaccharidases into the intestinal lumen and focal ultrastructural damage. These findings are consistent with previous observations $(10,14,19,22,23)$ of osmotic equilibration and intestinal damage in isolated duodenal and ileal loops as well as in intestinal preparations perfused directly with hypertonic solutions.

The extent of mucosal damage appears to be influenced by at least two factors: $(l)$ the degree of tonicity of the administered solutions and (2) the route of administration. Thus, in the earlier studies noted above, the most extensive damage was produced when as much as $50 \%$ glucose was perfused directly into the gut (14). In the present study, where the hyperosmotic agent was given into the stomach, intestinal damage was much milder (see Refs. 4 and 12 for discussion on gastric emptying and intestinal osmolality). We do not think our results are merely due to the pressure of the force-feeding alone, since controls that were force-fed isotonic mannitol or saline did not show any decrease in cell number and were morphologically intact.

Our enzymatic analysis suggests that the absorptive epithelial cells remaining on the jejunal surface after the hyperosmotic feeding are functionally intact; there was no decrease in the specific activities of intestinal disaccharidases on the brush border throughout the experimental period. We previously demonstrated that it takes several days of repeated hyperosmotic feedings to produce a decline in the specific activities of the mucosal disaccharidases (24). However, since there was a significant loss of mucosal disaccharidases into the intestinal lumen as well as a loss of cells from the jejunal mucosa, the total intestinal mucosal disaccharidase activity must be decreased (8)

The transient appearance of jejunal absorptive epithelial cells with shortened or "twinned" microvilli during the early phase of osmotic equilibration may reflect a process of damage to those cells that are being sloughed off the mucosa. Alternatively it could turn out that microvilli can retract and reextend in a manner recently demonstrated for isolated brush borders (20). Microvillar filaments are actin-like and bind heavy meromyosin (13). In our preparations we noted occasional morphologic connections between microfilaments in the core of microvilli and particulate aggregates in the terminal web region of some cells after a hyperosmotic load. This may represent a dissassembly of microfilament protein. Because of the complexity of filament systems within cells considerable caution is warranted in interpreting these observations (see Ref. 2 for discussion)

The disorganization of the lateral interdigitating plasma membranes of some adjacent epithelial cells during osmotic equilibration may also reflect reversible mucosal cell damage. Fragments of these plasma membranes appeared to bud off and fuse into larger structures. The increased numbers of autophagic vacuoles seen after 120 min suggests that much of the internalized plasma membrane undergoes intracellular degradation in lysosomes (for recent review see Ref. 11). Such modifications in the integrity of these lateral plasma membranes could be of pathophysiologic significance. This type of alteration might result in permeability changes that would allow the passage of toxins or allergens from the intestinal lumen into the circulation, or, might be a weak link permitting massive bacterial gas leakage into the submucosa resulting in pneumatosis intestinalis (1). Our own recent work supports the view that luminal hyperosmolality enhances the permeability of the rat jejunum to macromolecules (5). Other stresses, such as surgical trauma (25) or malnutrition (29), also enhance intestinal macromolecular permeability.

The osmotic pressure of unabsorbed carbohydrates and fermentative products within the lumen of the intestine of patients with diarrhea (16) results in secretion of fluids and electrolytes into the intestinal lumen until osmotic equilibrium is reached. The results from our present study suggest that hyperosmolality may account for the intestinal disaccharidase deficiencies induced during diarrheal disease (15). It should, of course, be borne in mind that the present results with a nonabsorbable osmotic agent, mannitol, may produce results that differ from those that would be obtained with a diffuseable or absorbable solute. Furthermore, other factors related to infection and disruption of enterocytes may also play a role in the pathophysiology of diarrhea in man $(15,16)$.

\section{REFERENCES AND NOTES}

1. Akesoda, F., Lifshitz, F., and Hoffman, K. M.: Transient monosaccharide intolerance in a newborn infant. Pediatrics, 51: 891 (1973).

2. Baudin, H., Stock, C., Vincent, P., and Grenier, J. F.: Microfilamentous system and secretion of enzyme in the exocrine pancreas. J. Cell Biol., 66: 165 (1975).

3. Book, L. S., Herbert, J. J., and Jung, A. L.: Necrotizing enterocolitis in infants fed an elemental formula. Pediat. Res., 8: 379 (1974).

4. Cooke, A. R.: Control of gastric emptying and mobility. Gastroenterology, 68 804 (1975).

5. Cooper, M., Teichberg. S., and Lifshitz. L.: Alterations in rat jejunal permeability to macromolecular tracer during a hyperosmotic load. Lab. Invest., 38: 447 (1978).

6. Dahlqvist, A.: Assay of intestinal disaccharidases. Enzym. Biol. Chem., 11: 52 (1970).

7. Friend, D. S. and Farquhar, M. G.: Functions of coated vesicles during protein 
absorption in the rat vas deterens. J. Cell Biol., 35: 357 (1967).

8. Gray, G. M.: Carbohydrate ingestion and absorption: Role of the small intestine. New Engl. J. Med., 292: 1225 (1975).

9. Helft, A. E., Brandwein, G. J., McNally, E. F., Neal, H. B., and Dennis, C. Effects of hypertonic glucose on small bowel motility and absorption. Minn. Med., 48: 1601 (1965).

10. Hindle, N., and Code, C.: Some differences between duodenal and ileal sorption. Amer. J. Physiol., 203: 215 (1972)

11. Holtzman, E.: Lysosomes: A survey. In: Cell Biology Monograph Series, SpringerVerlag. Vienna, 1975.

12. Hunt, J. N., and Pathak, J. D.: The osmotic effects of some simple molecules and ions on gastric emptying. J. Physiol. (Lond.), 154: 254 (1960).

13. Ishikawa, H., Bischoff, R., and Holtzer, H.: Formation of arrowhead complexes with heavy meromyosin in a variety of cell types. J. Cell Biol., 43: 312 (1969).

14. Kameda, H. T., Abei, T., Nasrallah, S. M., and Iber, F. L.: Functional and histological injury to intestinal mucosa produced by hypertonicity. Amer. J. Physiol., 214: 1090 (1968).

15. Lifshitz, F.: Clinical studies in diarrheal disease and malnutrition associated with carbohydrate intolerance. In: Proceedings on the Ninth International Congress on Nutrition, Mexico, 1972. Vol. 1, p. 173 (Karger, Basel, 1975).

16. Lifshitz, F., Coello-Ramierz, R., Gutierrez-Topete, G., and Coronado-Cornet. M. C. Carbohydrate intolerance in infants with diarrhea. J. Pediat., 79: 760 (1971).

17. Lowry, O. H., Rosebrough, N. J., Farr, A. L., and Randall, R. J.: Protein measurements with the Folin phenol reagent. J. Biol. Chem., 193: 265 (1951).

18. Malawer, S. J., and Powell, D. N.: An improved turbidometric analysis of polyethylene glycol utilizing an emulsifier. Gastroenterology, 53: 250 (1967).

19. Marner, I. L., Amdrup, E., Ludvigsen, J., and Jorgensen, N. S.: The electrolyte and protein concentration in hypertonic glucose solutions $15 \mathrm{~min}$ after intraintestinal injection of small intestinal sections of varying length. Enzymol. Biol. Chim., 2: 49 (1962).

20. Mooseaker, M. S.: Brush border motility. Microvillar contraction in triton-treated brush borders isolated from intestinal epithelium. J. Cell Biol., 71:417 (1976) 21. Nasrallah, S. M., and Iber, F. L.: Mannitol absorption in man. Amer. J. Med. Sci., 258: 80 (1969)

22. Nasrallah, S. M., Margolies, S., and Iber, F. L.: Fat and glucose malabsorption after hypertonic mannitol. Johns Hopkins Med. J., 127: 38 (1970).

23. Norris, H. T.: Responses of the small intestine to application of a hyperosmotic solution. Amer. J. Pathol., 73: 747 (1973).

24. Pergolizzi, R.. Lifshitz, F., Teichberg, S., and Wapnir, R. A.: Experimental osmotic diarshea: carbohydrate intake effects on intestinal disaccharidases. Amer. J. Clin. Nutr., 30: 482 (1977).

25. Rhodes, R. S., and Karnovsky, M. J.: Loss of macromolecular barrier function associated with surgical trauma to the intestine. Lab. Invest., 25: 220 (1971).

26. Schneider, W. C.: Phosphorous compounds in animal tissues: extraction and estimation of desoxypentose nucleic acid and pentose nucleic acid. J. Biol. Chem., 161: 293 (1945).

27. Seiber, F. B.: Removal of impurities, nucleic acid and polysaccharide from tuberculin protein. J. Biol. Chem., 133: 593 (1940).

28. Wehman, H. J., Plantholt, B. A., and Lifshitz, F.: Microvillous anomalies induced by various conditions of stress in the small intestine of the rat. Exp. Mol Pathol., 17: 296 (1972).

29. Worthington, B. S., Boatman. E. S., and Kenny, G. E.: Intestinal absorption of intact proteins in normal and protein-deficient rats. Amer. J. Clin. Vuts.. 2? 276 (1974)

30. We would like to thank Ms. Dale Bloom. Ms. Jacqueline Shomer, and Ms. Mary Ann Bayne for their excellent technical assistance.

31. This research was supported by NIH Grant NS 12148 to Dr. S. Teichherg.

32. Requests for reprints should be addressed to: Dr. Saul Teichberg. Pediatric Research Laboratory, North Shore University Hospital. Manhasset. NY 1]030) (USA).

33. Received for publication May 11, 1977.

34. Accepted for publication September 7.1977. 